\title{
Development of an Enriched Polyphenol (Natural Antioxidant) Extract from Orange Juice (Citrus sinensis) by Adsorption on Macroporous Resins
}

\author{
Luca Campone $\mathbb{C}^{1,2}$ Rita Celano $\mathbb{D}^{1},{ }^{3}$ Serena Rizzo, ${ }^{3}$ Anna Lisa Piccinelli, ${ }^{3}$ Luca Rastrelli $\mathbb{D},{ }^{3}$ \\ and Mariateresa Russo ${ }^{2}$ \\ ${ }^{1}$ Department of Biotechnology and Biosciences, University of Milano-Bicocca, Piazza Della Scienza 2, I-20126 Milan, Italy \\ ${ }^{2}$ Department of Agriculture, Food Chemistry Safety and Sensoromic Laboratory (FoCuSS Lab), University of Mediterranea, \\ Via Melissari, Reggio Calabria, RC, Italy \\ ${ }^{3}$ Department of Pharmacy, University of Salerno, Via Giovanni Paolo II, Fisciano, SA, Italy
}

Correspondence should be addressed to Luca Campone; lcampone@unisa.it

Received 16 October 2019; Revised 17 January 2020; Accepted 27 January 2020; Published 24 February 2020

Academic Editor: Anet Režek Jambrak

Copyright (c) 2020 Luca Campone et al. This is an open access article distributed under the Creative Commons Attribution License, which permits unrestricted use, distribution, and reproduction in any medium, provided the original work is properly cited.

Orange (Citrus sinensis) juice contains a high amount of antioxidant compounds, such as polyphenols and vitamins. The aim of this work was to develop an adsorption procedure for the quantitative recovery of polyphenols from fresh orange juice. Different macroporous resins have been selected to evaluate their affinity for phenolic compound in order to purify the antioxidant compounds from the orange juice. The main compounds of orange juice were firstly characterized using an UPLC-UV-HRMS to define the metabolite profile, and subsequently three different types of adsorbent (XAD-2, XAD-4, and XAD-16N) were tested to concentrate these bioactive compounds. The time of contact was selected based on kinetic studies, and subsequently the adsorption and elution conditions were optimized in order to maximize the recovery of phenolic compounds to obtain an extract rich of bioactive compounds. Lastly, antioxidant capacity of the orange juice extract of selected macroporous resin, obtained under optimized conditions, was determined by in vitro antioxidant assays.

\section{Introduction}

In the last few decades, the interest for new bioactive compounds in antioxidant compounds has increased because of their capability to fight several chronic and acute diseases, including inflammatory cardiovascular and neurological diseases as well as cancers [1].

Among these new compounds, polyphenol is considered one of the most promising antioxidants of natural origin that can be used for the formulation of new drugs and nutraceuticals and as ingredient for functional foods. Antioxidants are compounds that, present at low concentration, can significantly reduce or prevent the oxidation of other molecules.

The antioxidant compounds act through several mechanisms, but the most accepted one is the scavenging of free radicals contributing to reduce the oxidative stress [2].
Antioxidants are commonly used to protect oxidizable species, such as cosmetics [3,4], pharmaceuticals [5], and foods [6], from the deleterious effects of oxidation and are also employed as dietary supplements to neutralize the adverse effects of the oxidative stress. Moreover, they are also employed in the food industry to reduce rancidity, to protect and stabilize colours and aroma and to increase the shelf life of products [7]. Some synthetic additives with antioxidant activity, such as butylated hydroxytoluene (BHT) or butylated hydroxyanisole (BHA), are potentially toxic for humans [8]. For this reason, there has been a growing interest to replace synthetic antioxidants with natural ones in order to increase the shelf-life and improve the nutraceutical value of food products [7-9]. There is a broad range of natural antioxidant compounds, but, among them, polyphenol doubtlessly represents the most abundant and 
widespread class in nature. Polyphenols are secondary plant metabolites occurring in vegetables, fruits, beverages, and other related food products with well-documented antioxidant, anticarcinogenic, antimutagenic, antiallergic, and antiaging activities [10]; for these properties, particular attention is currently placed on its extraction from inexpensive agricultural food products. In this context, fruits and vegetables of the Mediterranean area can be considered an important source of polyphenol [11].

Although orange juice has lower antioxidant properties than the fruit juice of the berries (chokeberry, elderberry, and blueberry) $[12,13]$, orange juice can be considered a good source of polyphenol intake in the Mediterranean diet $[14,15]$. Citrus genus and its varieties are few of the most cultivated crops all over the world; in particular, thanks to its geographical location and climate, Italy is one of the major citrus producing nations in Europe after Spain [16]. Numerous population studies show that regular consumption of fruit and vegetables rich in antioxidants may prevent cardiovascular diseases. The nutritional benefits of citrus consumption on human health are well demonstrated [17-22], and over the past decades, a large number of studies have been carried out with the aim of identifying the bioactive components present in different parts of citrus fruits $[23,24]$ in an attempt to gain a deeper understanding of the correlation between diet, health benefits, and reduced risk of diseases $[17,25]$. In this context, several studies have associated the consumption of foods rich in phenolic compounds with lower risks of different types of cancer [26] and a decrease in the incidence of many diseases, as cardiovascular diseases (CVDs) [27]. Furthermore, these studies have shown that foods rich in phenolic compounds have an antioxidant, antiedematogenic, anti-inflammatory, and antiageing activity $[18,28]$ and may also contribute to an improvement of the blood lipid profile (e.g., triglyceride and total cholesterol reduction and increased HDL), a decrease of blood pressure and blood glucose or to the improvement of the endothelial function [29-33]. Citrus fruits are one of the richest dietary sources of flavonoids [34]. In recent years, the biological activity of citrus polyphenols and their role in the prevention and treatment of various human chronic and degenerative diseases have been extensively reported [35-37]. Given the possible increase of the commercial value of citrus juice as a natural source of antioxidant compounds, the aim of this work was to optimize and develop a method to obtain highly enriched antioxidant polyphenols and to eliminate other interfering compounds which do not possess antioxidant properties, such as proteins, sugars, fiber, or metals. In order to eliminate these interfering compounds and selectively recover the polyphenols, an easy, cheap, and green adsorption procedure has been developed. Experimental conditions affecting adsorption and elution of polyphenols from macroporous resin have been carefully studied and optimized.

\section{Materials and Methods}

2.1. Sample and Resin Extraction. Before being pressed, orange fruits were washed, peeled, and manually squeezed to obtain the juice. Pulps and solid material were removed by 5 minutes of centrifugation at $13000 \mathrm{rpm}$ (SL 16 centrifuge, Thermo Fisher Scientific, Milan, Italy). Amberlite macroporous resins XAD-2 XAD-4 and XAD-16N, used as adsorbent material, were obtained from sigma (Sigma-Aldrich, Germany), and information on the physical and chemical characteristics of each resin was reported in Table 1.

Before performing the extraction procedure, the macroporous resins were rinsed thoroughly with distilled water in order to remove salts and impurities, followed by a drying at $70^{\circ} \mathrm{C}$ for $24 \mathrm{~h}$, and finally immersed in ethanol for $12 \mathrm{~h}$. Ethanol was replaced by water before starting the adsorption procedure. Kinetic study was performed by keeping in contact $500 \mathrm{mg}$ of each resin with $10 \mathrm{~mL}$ of orange juice in a plastic tube of $50 \mathrm{~mL}$, under planetary agitation at $300 \mathrm{rpm}$ during the extraction time (30-240 $\mathrm{min})$ at constant temperature $\left(25^{\circ} \mathrm{C}\right)$. After the extraction, the resins were packed into empty SPE cartridge $(6 \mathrm{~mL})$, rinsed with deionized water, and end eluted with different ratios $(10: 0,3: 7,7: 3$, $0: 10 \mathrm{v} / \mathrm{v}$ ) of EtOH $: \mathrm{H}_{2} \mathrm{O}$ mixture, in order to select the best elution solvent. The final extract, at concentration of $5 \mathrm{mg} \cdot \mathrm{mL}^{-1}$, was injected and analysed by UHPLC-UV $(280 \mathrm{~nm})$.

2.2. Chemicals and Standards. MS-grade solvents used for UHPLC analysis, acetonitrile $(\mathrm{MeCN})$, water $\left(\mathrm{H}_{2} \mathrm{O}\right)$, and formic acid $(\mathrm{HCOOH})$ were provided by Romil (Cambridge, UK); analytical-grade solvent methanol ( $\mathrm{MeOH})$ and ethanol (EtOH) were supplied by Sigma-Aldrich (Milan, Italy). Water was purified by using a Milli-Q system (Millipore, Bedford, USA). Gallic acid (GA), 6-hydroxy-2,5,7,8-tetramethylchromane-2-carboxylic acid (Trolox), 2,2-diphenyl-1-picrylhydrazyl radical (DPPH), and Folin \& Ciocalteu's phenol reagent were purchased by Sigma-Aldrich (Milan, Italy).

2.3. UHPLC-UV-ESI-HRMS Conditions. Separation of phenolic compounds from citrus extract was performed on a Platin Blue system (Knauer GmbH, Berlin, Germany) consisting of a vacuum degasser, an autosampler, two UHPLC pumps, a column oven compartment, and a diodearray detector (DAD). The extract was chromatographed on a Kinetex C18 $(100 \times 2.1 \mathrm{~mm}$ I.D., $2.6 \mu \mathrm{m})$ column from Phenomenex (Torrance, CA, USA). Water (A) and acetonitrile (B), both acidified with $0.1 \% \mathrm{HCOOH}$, were used as mobile phases at flow rate of $0.4 \mathrm{~mL} \cdot \mathrm{min}^{-1}$. The gradient was programmed as follows: $0-1 \mathrm{~min} 2 \% \mathrm{~B} ; 0-1 \mathrm{~min} 2 \% \mathrm{~B}$; $1-3 \min 2-5 \% \mathrm{~B} ; 3-8 \mathrm{~min} 5-10 \% \mathrm{~B} ; 8-10 \mathrm{~min} 10-15 \%$ B held for $3 \mathrm{~min}$; $13-17 \mathrm{~min} 15-30 \% \mathrm{~B}$; $17-19 \min 30-50 \% \mathrm{~B}$; 19-21 min 50-85\% B; 21-23 min $85-98 \%$ B held for 4 min. Before the injection, the initial conditions were held for $5 \mathrm{~min}$ as the re-equilibration step. The injection volume was $10 \mu \mathrm{L}$, and the column was maintained at $30^{\circ} \mathrm{C}$. The UHPLC system was coupled to a DAD and a LTQ Orbitrap XL (Thermo Scientific, San Jose, CA) equipped with an electrospray ionisation source (ESI). The UV signal was acquired at three different wavelengths: 250, 285, and $365 \mathrm{~nm}$, whereas mass spectrometry acquisitions were carried out with the same condition previously reported [16]. Briefly, 
TABle 1: Chemical and physical properties of the resins used ${ }^{\mathrm{a}}$.

\begin{tabular}{lccccc}
\hline Resin name & Structure & Surface area $\left(\mathrm{m}^{2} / \mathrm{g}\right)$ & Pore diameter $\left(\mathrm{A}^{\circ}\right)$ & Dry density $(\mathrm{g} / \mathrm{mL})$ & Porosity $(\mathrm{mL} / \mathrm{g})$ \\
\hline XAD-2 & SDVB $^{\mathrm{b}}$ & 330 & 90 & 1.02 & 0.65 \\
XAD-4 & SDVB $^{\mathrm{b}}$ & 725 & 50 & 1.02 & 0.98 \\
XAD-16N & SDVB $^{\mathrm{b}}$ & 900 & 100 & 1.02 & 1.82 \\
\hline
\end{tabular}

${ }^{\mathrm{a}}$ Information provided by the manufacturers. ${ }^{\mathrm{b}} \mathrm{SDVB}$, styrene-divinylbenzene.

parameters for HRMS and $\mathrm{MS}^{\mathrm{n}}$ analysis were set using negative and positive ion modes with spectra acquired over a mass range from $100-800 \mathrm{~m} / z$ at a resolution of 60000 . The optimized value of ESI source were as follows: source voltage $3.5 \mathrm{kV}$, capillary voltage $42 \mathrm{~V}$, tube lens voltage $45.6 \mathrm{~V}$, capillary temperature $280^{\circ} \mathrm{C}$, sheath and auxiliary gas flow $\left(\mathrm{N}_{2}\right) 30$ and 10, respectively (arbitrary units). Collision energy for data dependent scans acquisition was set at 35 (arbitrary units). The Ms data were processed through Excalibur 2.2 software. Detected compounds were tentatively identified by comparing their retention time $\left(t_{\mathrm{R}}\right)$ with reference standard if avvaiable, or by using accurate mass (positive and negative ionisation) their MS/MS fragmentation, and bibliographic references.

\subsection{Determination of Total Phenolic Content (Folin Method).} The determination of total phenolic content (TC) was carried out according to the Folin-Ciocalteu method [38] using gallic acid as standard. $20 \mu \mathrm{L}$ of diluted XAD extract $\left(0.3 \mathrm{mg} \cdot \mathrm{mL}^{-1}\right)$ and $5 \mu \mathrm{L}$ of Folin-Ciocalteu reagent was diluted with $145 \mu \mathrm{L}$ of water reagent and mixed with $30 \mu \mathrm{L}$ of $\mathrm{Na}_{2} \mathrm{CO}_{3}(20 \% \mathrm{v} / \mathrm{v})$ in a 96-well microplate. After 45 minutes at $25^{\circ} \mathrm{C}$, the absorbance was read at $765 \mathrm{~nm}$ using a Multiskan Go spectrophotometer (Thermo Fischer Scientific). The results were expressed as $\mathrm{mg}$ of gallic acid equivalent (GAE)/g of extract as mean standard deviation (SD) of three independent measurements.

2.5. Radical DPPH Scavenging Activity. The $\mathrm{DPPH}^{\circ}$ assay was used to evaluate the antioxidant activity of all extracts; the parameters used were previously described by BrandWilliams et al. [39] with some modification in order to be performed in 96-well microplate. The experimental conditions were reported by Campone et al. [40] and were as follows: $5 \mu \mathrm{L}$ of XAD extracts in the range of $1-15 \mathrm{mg} \cdot \mathrm{mL}^{-1}$ was mixed to $195 \mu \mathrm{L}$ of $\mathrm{DPPH}^{\circ}$ standard solution at concentration of $120 \mu \mathrm{M}$, at room temperature, and protected from light. After $90 \mathrm{~min}$, the absorbance was read at $515 \mathrm{~nm}$ using a Multiskan Go spectrophotometer (Thermo Fischer Scientific). The DPPH assay expressed as $\mathrm{EC}_{50}$ was employed to quantify the antioxidant activity of the tested solution as mean standard deviation (SD) of three measurements.

2.6. Radical Cation ABTS $\bullet+$ Scavenging Activity. The radical scavenging capacity of XAD extracts was evaluated against ABTS generated by the chemical method, according to a previously reported protocol [41, 42], with some modification in order to be performed in a 96-well microplate. ABTS -+ radical was produced by reacting $7 \mathrm{mM} \mathrm{ABTS} \bullet+$ and $2.45 \mathrm{mM}$ potassium persulfate in the dark at room temperature $\left(25^{\circ} \mathrm{C}\right)$ for $16 \mathrm{~h}$ before its use. The aqueous ABTS $\bullet+$ solution was diluted with $5 \mathrm{mM}$ phosphate buffer ( $\mathrm{pH}$ 7.4) until an absorbance of $0.7( \pm 0.02)$ at $734 \mathrm{~nm}$ was achieved. $500 \mu \mathrm{L}$ of ABTS $\bullet+$ solution was mixed with $5 \mu \mathrm{L}$ of sample (5 different concentrations) in an eppendorf vial, and $300 \mu \mathrm{L}$ of the mixture was transferred into a 96-well microplate. The absorbance was measured at $734 \mathrm{~nm}$ every $5 \mathrm{~min}$ during $45 \mathrm{~min}$ in a microplate Multiskan Go spectrophotometer (Thermo Fischer Scientific). Trolox was used as reference standard, and the results were expressed as TEAC values (mmol of Trolox/g extract). These values were obtained from five different concentrations of each extract tested (between 1 and $4 \mathrm{mg} \cdot \mathrm{mL}^{-1}$ ) in the assay, giving a linear response between $20 \%$ and $80 \%$ blank absorbance. All analyses were done in triplicate.

2.7. Statistical Analysis. The statistical analysis was estimated using Statgraphic Centurion XVI Version 16.1 (Rockville, USA). Data were reported as mean (SD for triplicate determinations and analysis of variance (ANOVA) using Tukey's test were conducted to identify differences among means). Statistical significance was declared at $p<0.05$.

\section{Results and Discussion}

3.1. UHPLC-UV/HRMS Analysis. The chemical identification of polyphenol compounds in orange juice was made following the same procedure of the previously published paper [16]. Table 2 shows the list of 14 compounds tentatively identified by UHPLC-UV/MS/MS experiments.

In order to obtain complementary information useful to identify the main compounds in orange juice "Citrus sinensis" extract, the UHPLC-HRMS analysis was performed in both positive and negative ionisation modes. The compounds detected were tentatively characterized by means of MS data, together with the interpretation of MS/MS spectra, in comparison with those reported in the literature and with standard spectra, when available. In the identification process, the following database was used: ChemSpider (https://www.chemspider.com) and Scifinder (https:// scifinder.cas.org). Figure 1 shows the representative UV $(285 \mathrm{~nm})$ chromatogram of orange juice extracts obtained after the elution of XAD-16 under optimal conditions.

3.2. Selection of Macroporous Resin. After the characterization of orange juice, in order to select the best sorbent material to use, three different macroporous resins were tested to evaluate the adsorption of polyphenol compounds from orange juice. In order to evaluate the best resin and 
TABLE 2: UHPLC-HRMS/MS data of compounds detected in orange juice.

\begin{tabular}{|c|c|c|c|c|c|c|c|c|}
\hline \multirow{2}{*}{ N. } & \multicolumn{3}{|r|}{ (+) HRMS } & \multicolumn{3}{|r|}{ (-) HRMS } & \multirow{2}{*}{$\begin{array}{l}\text { Molecular } \\
\text { formula }\end{array}$} & \multirow{2}{*}{ Compound } \\
\hline & $m / z$ & ppm & Product ions MS/MS & $m / z$ & ppm & Product ions MS/MS & & \\
\hline 1 & 357.1165 & -4.8 & - & 355.1041 & 4.0 & 193.2711 [M-H-hexose $]^{-}$ & $\mathrm{C}_{16} \mathrm{H}_{20} \mathrm{O}_{9}$ & $\begin{array}{l}\text { Ferulic acid } \\
\text { glucoside }\end{array}$ \\
\hline 2 & 595.1627 & -4.2 & - & 593.1515 & 2.1 & $\begin{array}{l}\left.\text { 503.1201 [M-H- } \mathrm{C}_{3} \mathrm{H}_{6} \mathrm{O}_{3}\right]^{-} ; \\
473.1074\left[\mathrm{M}-\mathrm{H}-\mathrm{C}_{4} \mathrm{H}_{8} \mathrm{O}_{4}\right]^{-} ; \\
383.0773\left[\mathrm{M}-\mathrm{H}-\mathrm{C}_{7} \mathrm{H}_{14} \mathrm{O}_{7}\right]^{-}\end{array}$ & $\mathrm{C}_{27} \mathrm{H}_{30} \mathrm{O}_{15}$ & $\begin{array}{l}\text { Apigenin 6,8- } \\
\text { di-C-glucoside }\end{array}$ \\
\hline 3 & 625.1741 & -3.2 & - & 623.1624 & 3.4 & $\begin{array}{l}533.1317\left[\mathrm{M}-\mathrm{H}-\mathrm{C}_{3} \mathrm{H}_{6} \mathrm{O}_{3}\right]^{-} ; \\
403.1194\left[\mathrm{M}-\mathrm{H}-\mathrm{C}_{4} \mathrm{H}_{8} \mathrm{O}_{4}\right]^{-} ; \\
413.0868\left[\mathrm{M}-\mathrm{H}-\mathrm{C}_{7} \mathrm{H}_{14} \mathrm{O}_{7}\right]^{-}\end{array}$ & $\mathrm{C}_{28} \mathrm{H}_{32} \mathrm{O}_{16}$ & $\begin{array}{l}\text { Diosmetin } 6,8- \\
\text { di-C-glucoside }\end{array}$ \\
\hline 4 & $673.2434^{\mathrm{b}}$ & -3.9 & - & 649.2514 & 3.1 & $\begin{array}{c}605.2553\left[\mathrm{M}-\mathrm{H}-\mathrm{CO}_{2}\right]^{-} \\
443.2121\left[\mathrm{M}-\mathrm{H}-\mathrm{CO}_{2} \text {-hexose }\right]^{-}\end{array}$ & $\mathrm{C}_{32} \mathrm{H}_{42} \mathrm{O}_{14}$ & $\begin{array}{l}\text { Limonin- } \\
\text { glucoside }\end{array}$ \\
\hline 5 & 581.1838 & -4.1 & - & 579.1722 & 2.3 & $\begin{array}{c}17.1549[\mathrm{M}-\mathrm{H}-\mathrm{h} \text { exose }]^{-} \\
\text {271.0606 }[\mathrm{M}-\mathrm{H}-\text { hexose- } \\
\text { deoxyhexose }]^{-}\end{array}$ & $\mathrm{C}_{27} \mathrm{H}_{32} \mathrm{O}_{14}$ & Narirutin \\
\hline 6 & 435.1267 & -4.8 & - & 433.114 & 4.5 & $271.0588[\mathrm{M}-\mathrm{H}-\text { hexose }]^{-}$ & $\mathrm{C}_{21} \mathrm{H}_{22} \mathrm{O}_{10}$ & $\begin{array}{l}\text { Naringenin- } \\
\text { glucoside }\end{array}$ \\
\hline 7 & 611.1941 & -4.2 & - & 609.1831 & 3.7 & $\begin{array}{c}\text { 301.0723 [M-H-hexose- } \\
\text { deoxyhexose }]^{-}\end{array}$ & $\mathrm{C}_{28} \mathrm{H}_{34} \mathrm{O}_{15}$ & Hesperidin $^{\mathrm{a}}$ \\
\hline 8 & 465.1374 & -4.7 & - & 463.1247 & 2.0 & $301.0693{\text { [M-H-hexose }]^{-}}^{-}$ & $\mathrm{C}_{22} \mathrm{H}_{24} \mathrm{O}_{11}$ & $\begin{array}{l}\text { Hesperetin } \\
\text { glucoside }\end{array}$ \\
\hline 9 & $717.2701^{\mathrm{b}}$ & -3.2 & & 693.2767 & 2.4 & $633.2124[\mathrm{M}-\mathrm{H}-\mathrm{CH} 3 \mathrm{COOH}]^{-}$ & $\mathrm{C}_{34} \mathrm{H}_{46} \mathrm{O}_{15}$ & $\begin{array}{l}\text { Nomilin } \\
\text { glucoside }\end{array}$ \\
\hline 10 & $735.2807^{\mathrm{b}}$ & -3.3 & - & 711.2881 & 4.0 & $\begin{array}{c}651.2714\left[\mathrm{M}-\mathrm{H}-\mathrm{CH}_{3} \mathrm{COOH}\right]^{-} \\
607.2812\left[\mathrm{M}-\mathrm{H}-\mathrm{CH}_{3} \mathrm{COOH}-\right. \\
\left.\mathrm{CO}_{2}\right]^{-} \\
\end{array}$ & $\mathrm{C}_{34} \mathrm{H}_{48} \mathrm{O}_{16}$ & $\begin{array}{l}\text { Nomilinic acid } \\
\text { glucoside }\end{array}$ \\
\hline 11 & 471.1995 & -3.3 & - & $515.1924^{\mathrm{c}}$ & 3.5 & - & $\mathrm{C}_{27} \mathrm{H}_{30} \mathrm{O}_{10}$ & Limonin $^{\mathrm{a}}$ \\
\hline 12 & 373.1269 & -4.1 & $\begin{array}{c}358.1033\left[\mathrm{M}+\mathrm{H}-\mathrm{CH}_{3}\right]^{+} ; \\
343.0802\left[\mathrm{M}+\mathrm{H}-2 \mathrm{CH}_{3}\right]^{+} ; \\
329.1010\left[\mathrm{M}+\mathrm{H}-\mathrm{CO}-\mathrm{H}_{2} \mathrm{O}\right]^{+} \\
312.0985\left[\mathrm{M}+\mathrm{H}-\mathrm{CH}_{4}-2 \mathrm{CH}_{3}\right]^{+}\end{array}$ & & & - & $\mathrm{C}_{20} \mathrm{H}_{20} \mathrm{O}_{7}$ & Sinensetin \\
\hline 13 & 403.1372 & -4.7 & $\begin{array}{c}388.1135\left[\mathrm{M}+\mathrm{H}-\mathrm{CH}_{3}\right]^{+} \\
373.0905\left[\mathrm{M}+\mathrm{H}-2 \mathrm{CH}_{3}\right]^{+} \\
342.1093\left[\mathrm{M}+\mathrm{H}-\mathrm{CH}_{4}-2 \mathrm{CH}_{3}\right]^{+}\end{array}$ & & & - & $\mathrm{C}_{21} \mathrm{H}_{22} \mathrm{O}_{8}$ & Nobiletin \\
\hline 14 & 373.1266 & -4.0 & $\begin{array}{l}358.1034\left[\mathrm{M}+\mathrm{H}-\mathrm{CH}_{3}\right]^{+} \\
343.0802\left[\mathrm{M}+\mathrm{H}-2 \mathrm{CH}_{3}\right]^{+}\end{array}$ & & & - & $\mathrm{C}_{20} \mathrm{H}_{20} \mathrm{O}_{7}$ & Tangeretin \\
\hline
\end{tabular}

${ }^{\mathrm{a}}$ Compared with reference standards. ${ }^{\mathrm{b}} m / z$ values corresponding to $[\mathrm{M}+\mathrm{Na}]^{+} . m / z$ values corresponding to $[\mathrm{M}-\mathrm{H}+\mathrm{HCOOH}]^{-}$.

contact time able to remove analytes from orange juice, a kinetic study was performed. For this purpose, to obtain an adsorption curve of the target compounds, for each sorbent material at regular time interval, an aliquot was withdrawn and analysed by UHPLC-UV along a time of $240 \mathrm{~min}$ $(n=3)$. Pulp and solid material was removed from the juice by centrifugation. Subsequently, $10 \mathrm{~mL}$ of supernatant was taken by a calibrated glass pipette, placed in a $50 \mathrm{~mL}$ conical-bottomed test tube containing $500 \mathrm{mg}$ resins, and stirred by an orbital stirrer at a speed of $200 \mathrm{rpm} \cdot \mathrm{min}^{-1}$. Every 30 minutes, $100 \mu \mathrm{L}$ of sample was withdrawn using a micropipette and analysed by UHPLC in order to evaluate the adsorption kinetics of each analyte. Results of XAD-2 showed a very poor affinity (data not shown) of the analytes for the resin over the studied time $(240 \mathrm{~min})$. Based on these results, XAD-2 was not used for future experiments. Figure 2 shows the adsorption percentage (reduction) of each compound as function of the contact time (minutes)
(0-240 minutes) for each resin (XAD-4 and XAD-16N) at a temperature of $25^{\circ} \mathrm{C}$. The graphs related to XAD-4 (Figure 2(a)) and XAD-16N (Figure 2(b)) highlight a good affinity towards all compounds but with different absorption kinetics. Analysing accurately the kinetics related to XAD-16N, it is possible to notice a faster adsorption kinetics compared with those obtained using the XAD-4. When XAD-16N was used, an adsorption between 80-100\% was obtained in 2 hours for all the monitored compounds. The most lipophilic analytes follow a much more rapid adsorption kinetics compared with the analytes with medium and high polarity. This behaviour was predictable, considering the hydrophobic character of styrenedivinylbenzene resin. Similar results were obtained with XAD- 4 after a contact time of approximately 4 hours. Based on these results, XAD-16N and 120 minutes of contact time were selected as optimal conditions and seated for further experiments. 


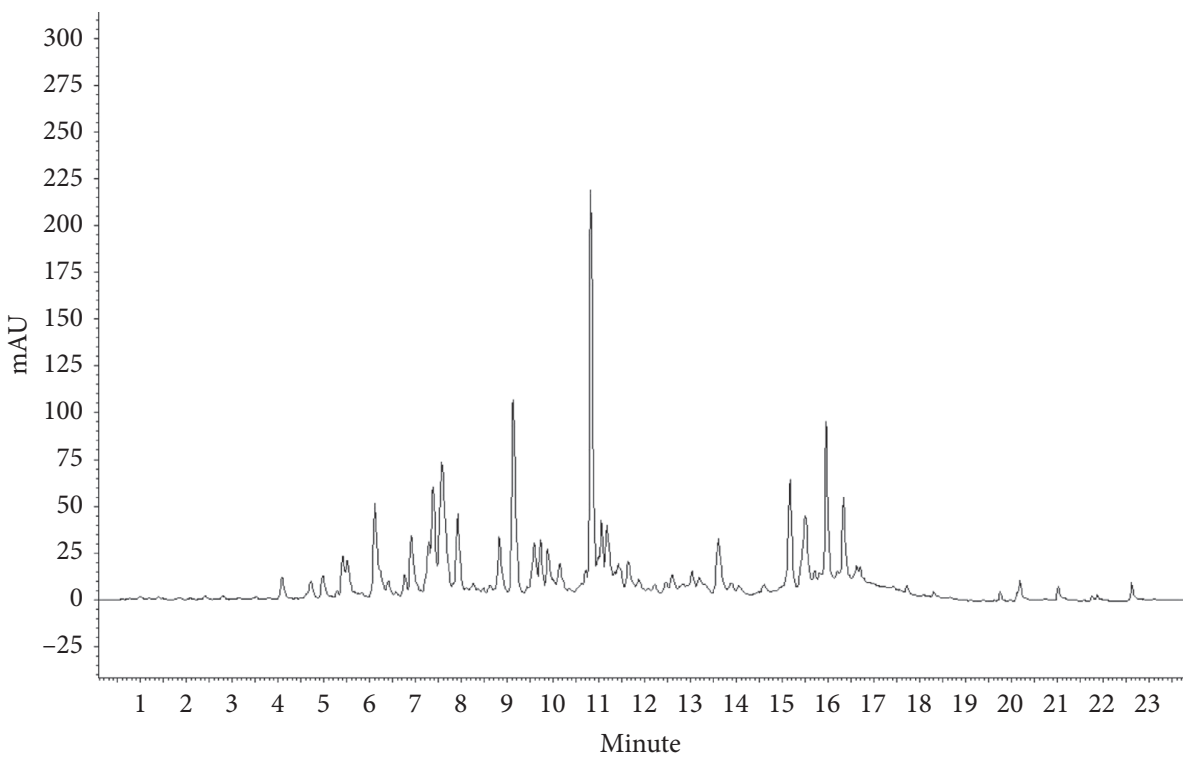

FIgURE 1: HPLC-UV profiles $(285 \mathrm{~nm})$ of orange juice extract (XAD-16N).

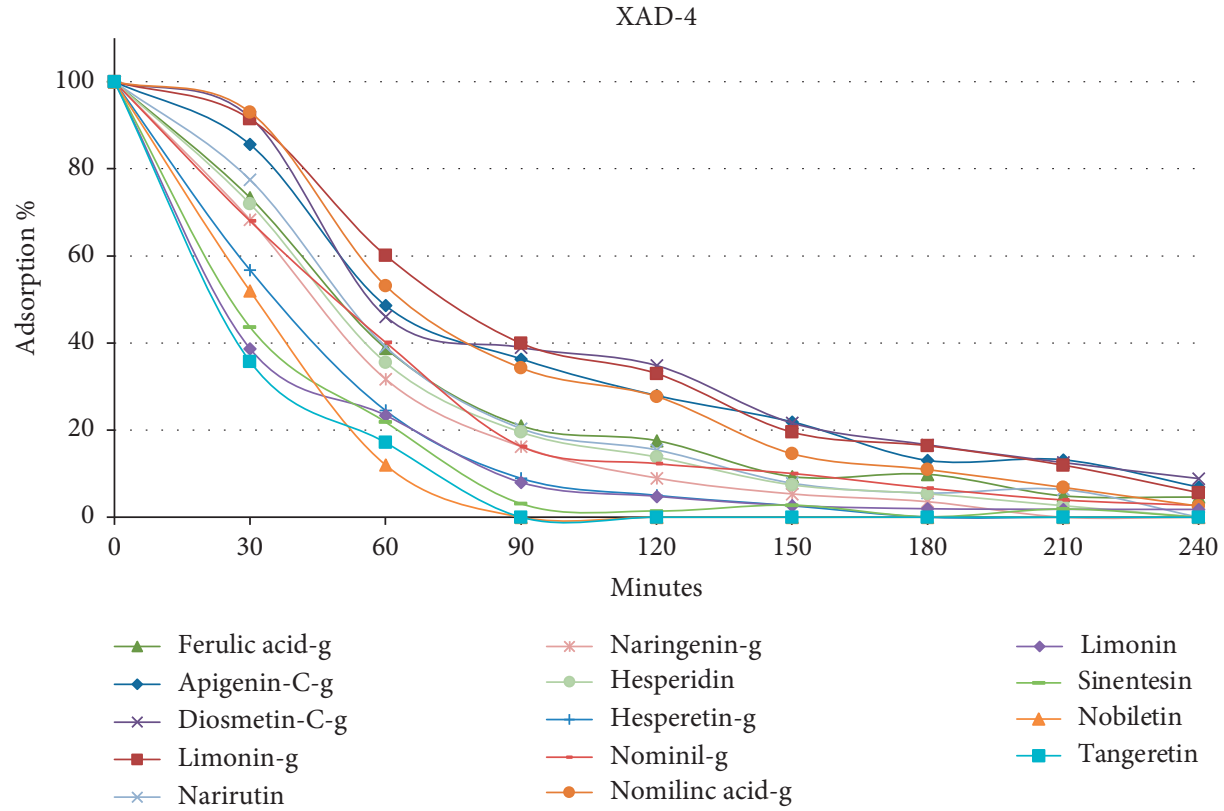

(a)

Figure 2: Continued. 


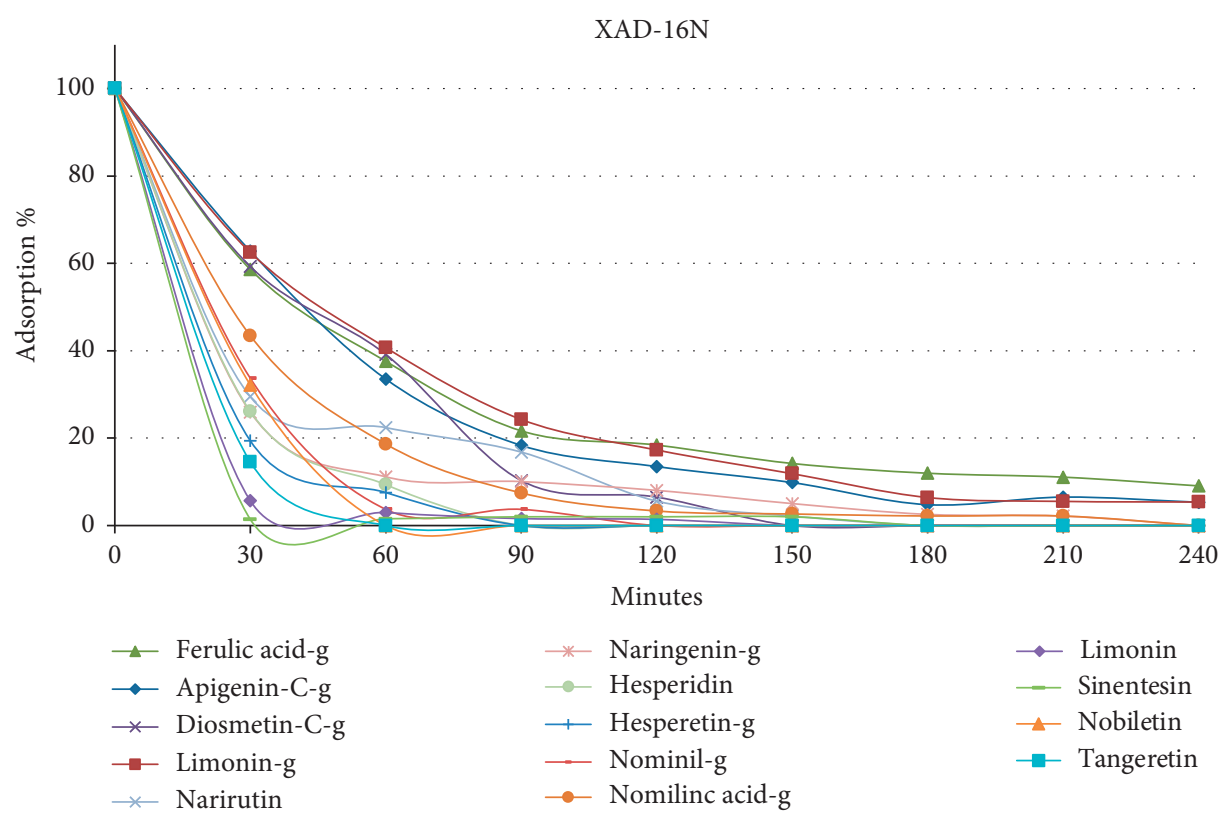

(b)

FIGURE 2: Adsorption kinetics of analytes using XAD-4 and XAD-16N macroporous resins.

3.3. Selection of Elution Solvent. After the selection of the macroporous resin able to quantitatively adsorb the phenolic compounds in the orange juice, the next step was the selection of an elution solvent to desorb the analytes from resin. In this step, the efficiency of different ratios $(10: 0,3$ : $7,7: 3$, and $0: 10 \mathrm{v} / \mathrm{v}$ ) of $\mathrm{EtOH}: \mathrm{H}_{2} \mathrm{O}$ mixture was evaluated. After the adsorption time, the resin XAD-16N was filtered and packed into $6 \mathrm{~mL}$ empty cartridges and subsequently rinsed with $5 \mathrm{~mL}$ of deionized water to remove sugars and nonadsorbed compounds. After washing the resin with $10 \mathrm{~mL}$ of pure water, $10 \mathrm{~mL}$ of ethanol and different ratios $(7: 3$, and $3: 7 \mathrm{v} / \mathrm{v})$ of $\mathrm{EtOH}: \mathrm{H}_{2} \mathrm{O}$ mixture were passed through the cartridge. After 30 minutes, the elution solvent passed through the cartridge in order to elute and collect the analytes into a test tube. The results show a similar trend when pure water and ethanol were used as elution solvent, producing low recovery for all target analytes (Figure 3). As shown in Figure 3, the best extraction efficiency was obtained using ethanol $70 \%$, while the extraction efficiency of target compounds decreased drastically when all the other combinations of elution solvent were used.

On the basis of these results, EtOH: $\mathrm{H}_{2} \mathrm{O}$ 7:3 v/v mixture was selected as optimal elution solvent and was used for further experiments. Another important parameter that was studied and optimized was the contact time between the selected elution solvents and the XAD16 N. As shown in Figure 4, by increasing the contact time between elution solvent and resin before performing the elution, the extraction yield increases up to $60 \mathrm{~min}$ and then remains almost constant for the rest of the experiment time (120 $\mathrm{min})$; therefore, $60 \mathrm{~min}$ was selected as best contact time.
3.4. Antioxidant Capacity of Orange Juice Extract. Nowadays, the biological effects of polyphenol on human health are widely demonstrated by several studies, showing that citrus extract has a good antioxidant activity [1]. Therefore, citrus juice extract can be used as a potential source of bioactive compounds for the development of natural ingredients to be used in the nutraceutical industry or as foods additives. Before the evaluation of the antioxidant capacity of juice extracts, the total phenol content was evaluated by the Folin-Ciocalteu method [38]. The results of the Folin-Ciocalteu assay showed a good content of phenolic compounds in the XAD-16 extract (356.5 $\pm 4 \mathrm{mg} \mathrm{GAE} /$ $\mathrm{g}$ of extract). The presence of a high content of phenolic compounds provided by the Folin-Ciocalteu assay suggested the possibility of a high antioxidant capacity. Whereby, in order to evaluate the antioxidant capacity of the XAD-16N extract, in vitro antioxidant activity assays DPPH and ABTS were performed. Unlike most of the other antioxidant assays used to evaluate the AOC, it is based on a single electron and/or hydrogen atom transfer reaction (SET/HAT) and the DPPH and ABTS assays are based on SET/HAT simultaneously [43], providing a more representative evaluation of antioxidant properties. In order to avoid the underestimation of the results, before the estimation of AOC, the optimization of reaction time and concentration range for both standard (Trolox) and extract were carried out. The AOC provided by the DPPH assay, expressed as $\mathrm{EC}_{50}\left(9.97 \pm 0.5 \mu \mathrm{g} \cdot \mathrm{mL}^{-1}\right)$, whereas the TEAC values provided by the ABTS assay were $3.88 \mathrm{mmol}$ of Trolox/g extract. Good polyphenol content shows a significant radical scavenger activity to the extract, as demonstrated by the results of DPPH and ABTS assays. This result indicates that the orange juice extract can be used as source 


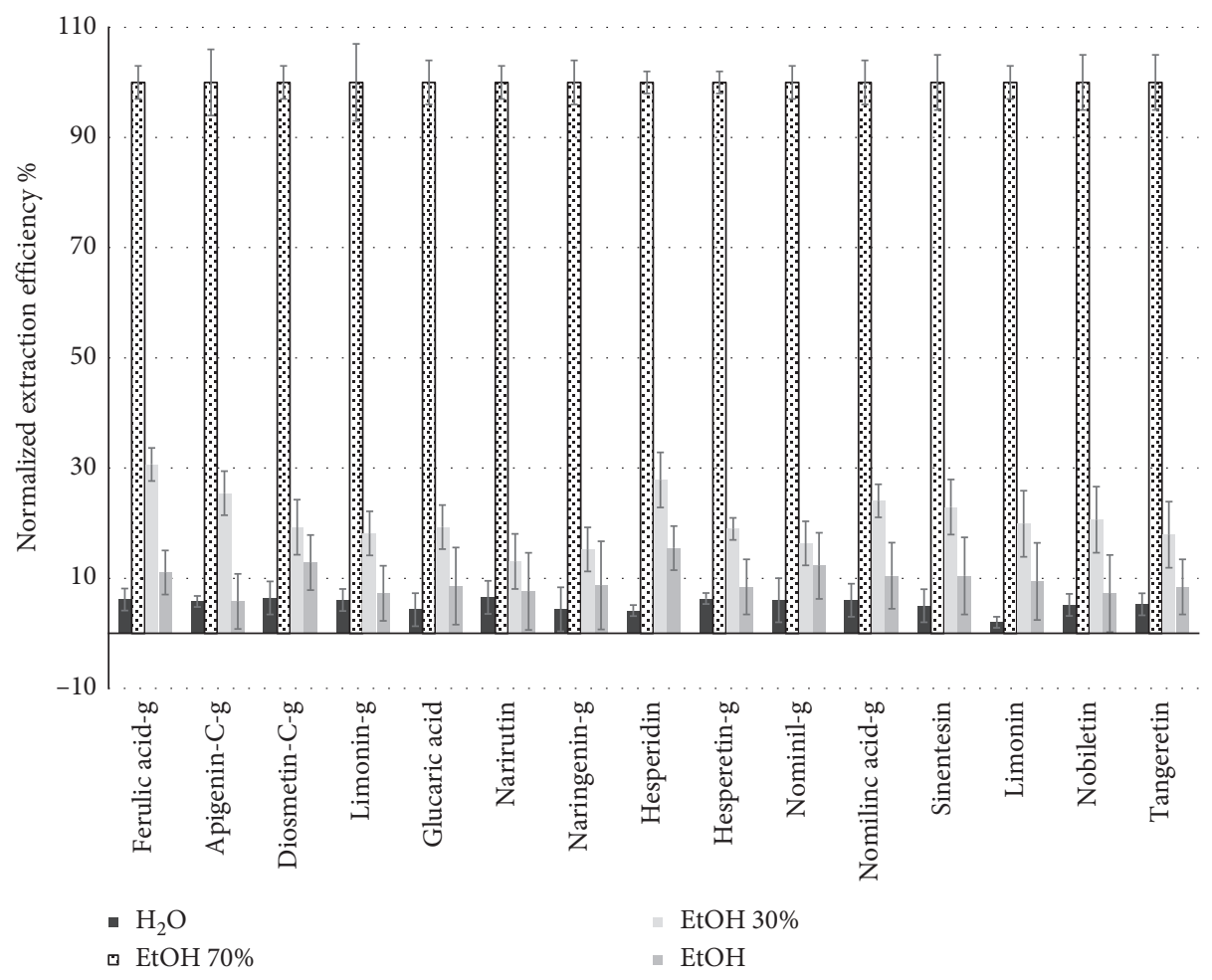

FIGURE 3: Normalized extraction efficiency of target analytes using different elution solvents. Values are means of three replicates \pm relative standard deviation (RDS\%).

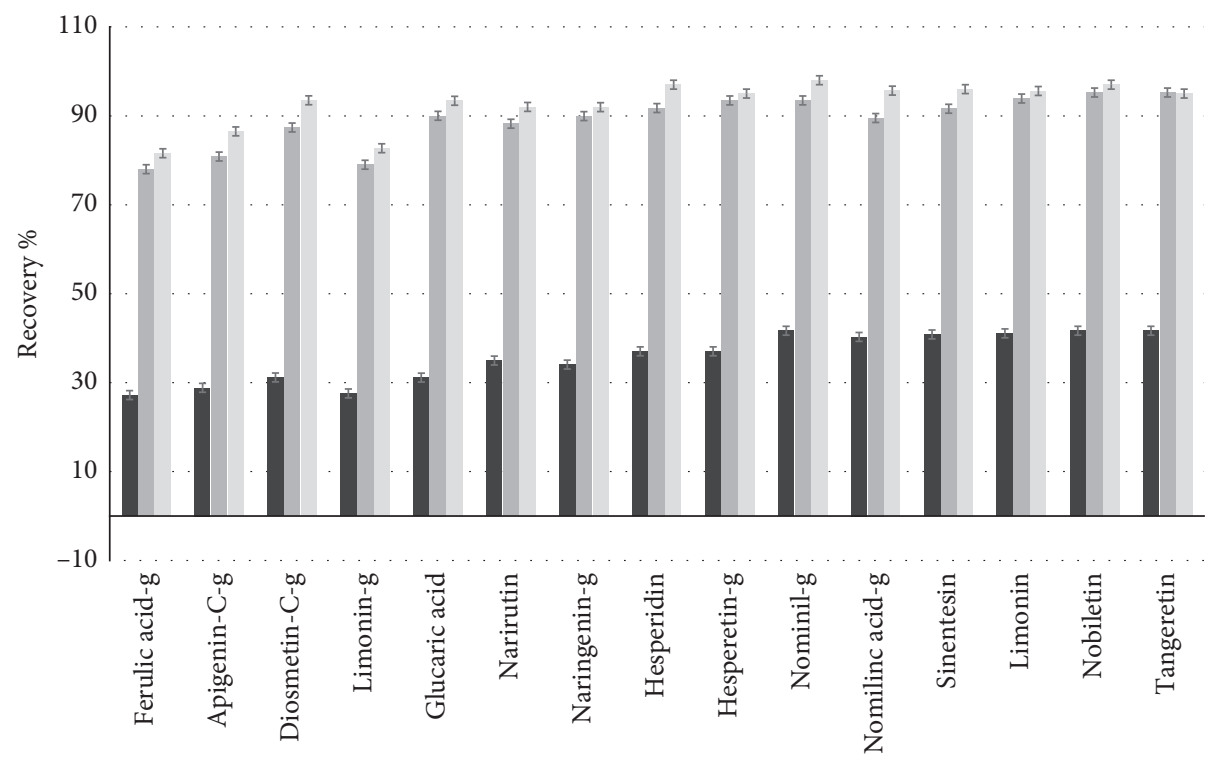

$$
\begin{aligned}
& \text { - } 30 \mathrm{~min} \\
& -60 \mathrm{~min} \\
& -120 \mathrm{~min}
\end{aligned}
$$

FIGURE 4: Recovery percentage of target analytes using different contact times of elution solvents and macroporous resin. Values are means of three replicates \pm relative standard deviation (RDS\%). 
of food ingredient or as natural ingredient in the nutraceutical industry.

\section{Conclusions}

The adsorption of phenolic compounds from orange juice on macroporous resin was studied in order to develop an easy and favourable process to obtain an extract with antioxidant properties. The main parameters affecting the extraction efficiency and elution process were optimized. The results show that, in order to obtain an excellent extraction efficiency for analytes, the adsorption needs a long contact time, with the most effective resin requiring a time of two hours to reach the equilibrium. The resin that showed the best result regarding the adsorption of phenolic compounds was XAD$16 \mathrm{~N}$. A mixture of $\mathrm{EtOH}: \mathrm{H}_{2} \mathrm{O}(7: 3 \mathrm{v} / \mathrm{v})$ was selected as the best elution solvent used in order to obtain a quantitative recovery of target analytes. Subsequently, the total polyphenol content and the antioxidant activity of extract were evaluated by using in vitro antioxidant assays. The results demonstrate that the orange juice extract represents a rich source of antioxidant phenolic compounds that could be employed as additives to prevent the oxidation of foodstuffs but also as functional ingredients in the nutraceutical industry.

\section{Data Availability}

The data used to support the findings of this study are available from the corresponding author upon request.

\section{Conflicts of Interest}

The authors declare no conflicts of interest regarding the publication of this study.

\section{Authors' Contributions}

Luca Campone performed some experiments, analysed and interpreted the results, and drafted the manuscript. Rita Celano performed the HPLC-HRMS experiments and contributed to the statistical analysis. Serena Rizzo performed the antioxidant experiments and contributed to the statistical analysis. AnnaLisa Piccinelli supported the interpretation of results. Luca Rastrelli supported the interpretation of results and revised the manuscript. MariaTeresa Russo designed the overall experimental scheme and revised the manuscript. All authors approved the final version of the manuscript.

\section{Acknowledgments}

This work was financially supported by the "Modelli Sostenibili e Nuove Tecnologie per la Valorizzazione delle Filiere Vegetali Mediterranee" (project number PON03 PE_00090_3) and by the Research Infrastructure Saf@ med-Food Safety Platform (grant number PONa3_00016). The authors are grateful to Dr. Sara Rizzo for her English language support.

\section{References}

[1] A. Scalbert, I. T. Johnson, and M. Saltmarsh, "Polyphenols: antioxidants and beyond," The American Journal of Clinical Nutrition, vol. 81, no. 1, pp. 215S-217S, 2005.

[2] V. Lobo, A. Patil, A. Phatak, and N. Chandra, "Free radicals, antioxidants and functional foods: impact on human health," Pharmacognosy Reviews, vol. 4, no. 8, p. 118, 2010.

[3] S. K. Katiyar and C. A. Elmets, "Green tea polyphenolic antioxidants and skin photoprotection," International Journal of Oncology, vol. 18, pp. 1307-1313, 2001.

[4] M. P. Lupo, "Antioxidants and vitamins in cosmetics," Clinics in Dermatology, vol. 19, no. 4, pp. 467-473, 2001.

[5] S. Oksana, B. Marian, R. Mahendra, and S. H. Bo, "Plant phenolic compounds for food, pharmaceutical and cosmetics production," Journal of Medicinal Plants Research, vol. 6, no. 13, pp. 2526-2539, 2012.

[6] J. M. Lorenzo, P. E. S. Munekata, A. S. Sant'Ana et al., "Main characteristics of peanut skin and its role for the preservation of meat products," Trends in Food Science \& Technology, vol. 77, pp. 1-10, 2018.

[7] S. Dudonné, X. Vitrac, P. Coutière, M. Woillez, and J.-M. Mérillon, "Comparative study of antioxidant properties and total phenolic content of 30 plant extracts of industrial interest using DPPH, ABTS, FRAP, SOD, and ORAC assays," Journal of Agricultural and Food Chemistry, vol. 57, no. 5, pp. 1768-1774, 2009.

[8] R. Celano, A. L. Piccinelli, I. Pagano et al., "Oil distillation wastewaters from aromatic herbs as new natural source of antioxidant compounds," Food Research International, vol. 99, pp. 298-307, 2017.

[9] F. Shahidi and P. Ambigaipalan, "Phenolics and polyphenolics in foods, beverages and spices: antioxidant activity and health effects-a review," Journal of Functional Foods, vol. 18, pp. 820-897, 2015.

[10] H. El Gharras, "Polyphenols: food sources, properties and applications-a review," International Journal of Food Science \& Technology, vol. 44, no. 12, pp. 2512-2518, 2009.

[11] I. Pagano, A. L. Piccinelli, R. Celano et al., "Chemical profile and cellular antioxidant activity of artichoke by-products," Food \& Function, vol. 7, no. 12, pp. 4841-4850, 2016.

[12] D. Nowak, M. Gośliński, and A. Szwengiel, "Multidimensional comparative analysis of phenolic compounds in organic juices with high antioxidant capacity," Journal of the Science of Food and Agriculture, vol. 97, no. 8, pp. 2657-2663, 2017.

[13] D. Granato, A. R. Karnopp, and S. M. van Ruth, "Characterization and comparison of phenolic composition, antioxidant capacity and instrumental taste profile of juices from different botanical origins," Journal of the Science of Food and Agriculture, vol. 95, no. 10, pp. 1997-2006, 2015.

[14] U. Justesen, P. Knuthsen, and T. Leth, "Determination of plant polyphenols in Danish foodstuffs by HPLC-UV and LC-MS detection," Cancer Letters, vol. 114, no. 1-2, pp. 165-167, 1997.

[15] F. Visioli and C. Galli, "The role of antioxidants in the Mediterranean diet," Lipids, vol. 36, no. S1, pp. S49-S52, 2001.

[16] R. Celano, L. Campone, I. Pagano et al., "Characterisation of nutraceutical compounds from different parts of particular species of Citrus sinensis "Ovale Calabrese"by UHPLC-UVESI-HRMS," Natural Product Research, vol. 33, no. 2, pp. 244-251, 2019.

[17] D. Gonçalves, P. Ferreira, E. Baldwin, and T. Cesar, "Health benefits of orange juice and citrus flavonoids," Phytochemicals 
in Citrus: Applications in Functional Foods, CRC Press, Boca Raton, FL, USA, 2017.

[18] T. Mencherini, L. Campone, A. L. Piccinelli et al., "HPLCPDA-MS and NMR characterization of a hydroalcoholic extract of citrus aurantium L. var. amara Peel with antiedematogenic activity," Journal of Agricultural and Food Chemistry, vol. 61, no. 8, pp. 1686-1693, 2013.

[19] A. L. Piccinelli, M. García Mesa, D. M. Armenteros et al., "HPLC-PDA-MS and NMR characterization of C-glycosyl flavones in a hydroalcoholic extract of Citrus aurantifolia leaves with antiplatelet activity," Journal of Agricultural and Food Chemistry, vol. 56, no. 5, pp. 1574-1581, 2008.

[20] C.-N. Zhao, X. Meng, Y. Li et al., "Fruits for prevention and treatment of cardiovascular diseases," Nutrients, vol. 9, no. 6, p. 598, 2017.

[21] C. Heiss, C. L. Keen, and M. Kelm, "Flavanols and cardiovascular disease prevention," European Heart Journal, vol. 31, no. 21 , pp. 2583-2592, 2010.

[22] F. J. He, C. A. Nowson, M. Lucas, and G. A. MacGregor, "Increased consumption of fruit and vegetables is related to a reduced risk of coronary heart disease: meta-analysis of cohort studies," Journal of Human Hypertension, vol. 21, no. 9, pp. 717-728, 2007.

[23] A. Salvo, M. Bruno, G. L. La Torre et al., "Interdonato lemon from Nizza di Sicilia (Italy): chemical composition of hexane extract of lemon peel and histochemical investigation," Natural Product Research, vol. 30, no. 13, pp. 1517-1525, 2016.

[24] N. Cicero, C. Corsaro, A. Salvo et al., "The metabolic profile of lemon juice by proton HR-MAS NMR: the case of the PGI Interdonato Lemon of Messina," Natural Product Research, vol. 29, no. 20, pp. 1894-1902, 2015.

[25] R. H. Liu, "Health benefits of fruit and vegetables are from additive and synergistic combinations of phytochemicals," The American Journal of Clinical Nutrition, vol. 78, no. 3, pp. 517S-520S, 2003.

[26] L. H. Yao, Y. M. Jiang, J. Shi et al., "Flavonoids in food and their health benefits," Plant Foods for Human Nutrition, vol. 59, no. 3, pp. 113-122, 2004.

[27] P. M. Kris-Etherton, K. D. Hecker, A. Bonanome et al., "Bioactive compounds in foods: their role in the prevention of cardiovascular disease and cancer," The American Journal of Medicine, vol. 113, no. 9, pp. 71-88, 2002.

[28] O. Benavente-García and J. Castillo, "Update on uses and properties of citrus flavonoids: new findings in anticancer, cardiovascular, and anti-inflammatory activity," Journal of Agricultural and Food Chemistry, vol. 56, no. 15, pp. 61856205, 2008.

[29] D. Nowak, M. Gośliński, A. Wesołowska, K. Berenda, and C. Popławski, "Effects of acute consumption of noni and chokeberry juices vs. energy drinks on blood pressure, heart rate, and blood glucose in young adults," Evidence-Based Complementary and Alternative Medicine, vol. 2019, Article ID 6076751, 9 pages, 2019.

[30] J. Chrzczanowicz, A. Gawron, A. Zwolinska et al., "Simple method for determining human serum 2,2-diphenyl-1-picrylhydrazyl (DPPH) radical scavenging activity-possible application in clinical studies on dietary antioxidants," Clinical Chemical Laboratory Medicine, vol. 46, no. 3, pp. 342-349, 2008.

[31] A. J. Flammer, E. A. Martin, M. Gössl et al., "Polyphenol-rich cranberry juice has a neutral effect on endothelial function but decreases the fraction of osteocalcin-expressing endothelial progenitor cells," European Journal of Nutrition, vol. 52, no. 1, pp. 289-296, 2013.
[32] J. Zheng, Y. Zhou, S. Li et al., "Effects and mechanisms of fruit and vegetable juices on cardiovascular diseases," International Journal of Molecular Sciences, vol. 18, no. 3, p. 555, 2017.

[33] I. Banjari, A. Misir, K. Šavikin et al., "Antidiabetic effects of Aronia melanocarpa and its other therapeutic properties," Frontiers in Nutrition, vol. 4, p. 53, 2017.

[34] M. Berhow, B. Tisserat, K. Kanes, and C. Vandercook, Survey of Phenolic Compounds Produced in Citrus, USDA, Champaign, IL, USA, 1998.

[35] E. Middleton, "Potential health-promoting properties of citrus flavonoids," Food Technology, vol. 48, pp. 115-119, 1994.

[36] J. A. Attaway, Citrus Juice Flavonoids with Anticarcinogenic and Antitumor Properties, ACS Publications, Washington, DC, USA, 1994.

[37] M. E. Bracke, "Citrus flavonoid effect on tumor invasion and metastasis: the citrus flavonoid tangeretin may inhibit the processes that shorten the life expectancy of tumor-bearing partients," Food Technology, vol. 48, pp. 121-124, 1994.

[38] V. L. Singleton, R. Orthofer, and R. M. Lamuela-Raventós, "[14] Analysis of total phenols and other oxidation substrates and antioxidants by means of folin-ciocalteu reagent," in Methods in Enzymology, pp. 152-178, Elsevier, Amsterdam, Netherlands, 1999.

[39] W. Brand-Williams, M. E. Cuvelier, and C. Berset, "Use of a free radical method to evaluate antioxidant activity," LWT-Food Science and Technology, vol. 28, no. 1, pp. 25-30, 1995.

[40] L. Campone, R. Celano, A. Lisa Piccinelli et al., "Response surface methodology to optimize supercritical carbon dioxide/co-solvent extraction of brown onion skin by-product as source of nutraceutical compounds," Food Chemistry, vol. 269, pp. 495-502, 2018.

[41] R. Re, N. Pellegrini, A. Proteggente, A. Pannala, M. Yang, and C. Rice-Evans, "Antioxidant activity applying an improved ABTS radical cation decolorization assay," Free Radical Biology and Medicine, vol. 26, no. 9-10, pp. 1231-1237, 1999.

[42] A. P. Sánchez-Camargo, J. A. Mendiola, A. Valdés et al., "Supercritical antisolvent fractionation of rosemary extracts obtained by pressurized liquid extraction to enhance their antiproliferative activity," The Journal of Supercritical Fluids, vol. 107, pp. 581-589, 2016.

[43] R. L. Prior, X. Wu, and K. Schaich, "Standardized methods for the determination of antioxidant capacity and phenolics in foods and dietary supplements," Journal of Agricultural and Food Chemistry, vol. 53, no. 10, pp. 4290-4302, 2005. 